\title{
Topical Delivery of Methocarbamol Loaded Nanoemulgel - in vitro Characterization
}

\author{
Abimanyu Sugumaran, ${ }^{*}$ Vishali Mathialagan \\ Department of Pharmaceutics, SRM College of Pharmacy, SRM Institute of Science and Technology, Kattankulathur, Chengalpattu, \\ Tamil Nadu, INDIA.
}

\begin{abstract}
Background: Methocarbamol is used as skeletal muscle relaxant. Nanoemulgel is currently being developed as a transdermal drug delivery technology because to its nanosized droplets, which provide superior effectiveness with reduced toxicity. Aim: The aim of the study is to prepare and characterize the Methocarbamol loaded nanoemulgel. Materials and Methods: The required quantity of Methocarbamol dissolved in Acconon oil, surfactant and co-surfactant used to prepare nanoemulsion with various ratios using probe sonicator and poured into the prepared carbopal gel with constant stirring. The prepared nanomelgel was characterized for its $\mathrm{pH}$, viscosity, particle size and zeta potential, surface morphology by TEM, drug content and in-vitro Methocarbamol release from developed formulation. Results: The developed NEs formulation exhibited acceptable $\mathrm{pH}$ range around 6 to 7 , viscosity was in the range of $38.26 \mathrm{cps}$ to $45.25 \mathrm{cps}$. The average droplet size of the NE formulations varied from 20.1 to $56.4 \mathrm{~nm}$. There is no much change of droplet size when varying the oil concentration of the NEs. The result of the droplet polydispersity index (PDI) shows the droplets are uniformly distributed. The zeta potential of the formulations ranging from $-0.1 \mathrm{mV}$ to $0.3 \mathrm{mV}$ for NE and NE-Gel respectively. This is due to the presence of the non-ionic surfactant over the droplet. The TEM micrograph of the $10 \%$ NEs and NE-Gel appears spherical in nature with drug embedded in the oil droplet. The volume of drug release for $3 \%$ Nanoemulsion is $64.28 \%, 50.78 \%, 41.78 \%, 38.57 \%$ and $3 \%$ Nanoemulgel is $29.57 \%, 38.25 \%$, $43.71 \%, 52.39 \%$ respectively. Due to higher quantity of oil phase of NE and rigid gel nature the in-vitro resulted in delaying and sustaining in drug release. Conclusion: Hence, we conclude that the developed NE, NE-Gel might be beneficial for the better topical delivery of muscle relaxant.
\end{abstract}

Key words: Methocarbamol, Nanoemulsion, Nanoemulgel, Topical Delivery, In-vitro characterization.

\section{INTRODUCTION}

A muscle cramp is an unexpected, automatic, excruciating compression of a muscle either part of it. This myoelectric movement could be mentioned as "cramp release". Cramps can happen in cases among low motor neuron disorder, metabolic disorder, neuropathies, and intense extracellular exhaustion. Moreover, they frequently occur in normal person along with no data of apprehensive or metabolic disorder, for example in rest, gestation and heavy physical workouts. The cramps have characterized as "benign cramps" or idiopathic cramps or spasms without clear reason. ${ }^{1}$

Lack of hydration (and additionally electrolyte consumption) frequently is inclined as a clarification for muscle cramps happening in laborers and sports person. The major risk factors for exercise were muscle cramp acquired from genetic history of cramping, any cramps by accident, over workouts or after workouts, insufficient stamina for the action..$^{2-4}$ Muscle relaxants is one of the several therapies recently worked in the system of normal low back pain.
Submission Date: 12-04-2021; Revision Date: 02-06-2021; Accepted Date: 10-09-2021.

DOI: $10.5530 /$ ijper.56.1.17 Correspondence: Dr. Abimanyu Sugumaran Professor, Department of Pharmaceutics, SRM College of Pharmacy, SRM Institute of Science and Technology,

Kattankulathur-603203, Chengalpattu, Tamil Nadu, INDIA.

Email - abipharmastar@ gmail.com

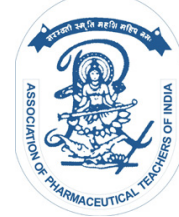

www.ijper.org 
$35 \%$ of patients concern to care doctors for low back pain are prescribed muscle relaxants., ${ }^{5,6}$ It is feasible as a short-term symptomatic aid in patients suffering from severe and persistent low back pain. However, tiredness, dizziness, and other negative effects are common. Generally musculoskeletal conditions provoke fragility along with muscle pain contain fibromyalgia, ${ }^{7}$ strain cerebral pains, myofascial agony, and mechanical low back or neck pain.

Skeletal muscle relaxant is one of a few classifications of medication as often as possible utilized to treat these cases. ${ }^{7-11}$ Centrally acting medications are helpful in musculoskeletal pain and spastic neurological spasm, for example, cerebral paralysis and these drugs may cause many adverse side effects. ${ }^{12,13}$

Methocarbamol is a BCS class-II tranquilize, having low fluid dissolvability and high penetrability. Methocarbamol is carbamic acid ester, a secondary of guaifenesin carbamate. In market, it is available in film coated tablets but on set action slow while paining it gives muscle relaxation. Pharmacologically, methocarbamol is a centrally acting muscle relaxant, but in general it acts as antidepressant on central nervous system. Sedative and analgesic reaction has also been proved. Methocarbamol is a viable solution for neck and back pain, fibromyalgia, strain cerebral pains and myofascial torment disease $\mathrm{e}^{14-17}$ and well endured restorative choice for the intense low back pain patients. Topical delivery of these drugs provides better local action with less severe adverse effect. But the conventional topical delivery methods show lesser efficacy due to poor solubility of drugs. ${ }^{18}$

Nanoemulgels are utilized as potential drug delivery system with several routes such as topical, and oral. ${ }^{19}$ The technical usage of nanoemulgel expandingly being utilized in variety of organization because of their typical properties, small globules size are $20-200 \mathrm{~nm}$ within huge interface area with increased solubilizing capacity, transparent, viscosity is low and enhanced kinetics stability, flocculation and coalescence in any cases. ${ }^{20-23}$ Firstly, the solubility of lipophilic drug increased within the oil of the nanoemulsion followed by incorporated into a gel base has an important criterion to increase the colloidal stabilization ${ }^{2426}$ by improving its viscosity of aqueous phase for better treatment on topically. ${ }^{27,28}$ Hence, we planned to develop the nanoemulgel for the better topical delivery of methocarbamol through the intact skin.

The present aim of this work is to develop and optimise a stable nanoemulgel loaded Methocarbamol, by ultra-sonication method. The excipients used such as oils, surfactants, co-surfactants possess various physico-chemical properties. ${ }^{29}$ Further the developed formulations have determined the compatibility studies by FT-IR (Fourier Transform - IR Analysis), particle size and zeta potential by zeta sizer, $\mathrm{pH}$, viscosity, gel spreadability, surface morphology by TEM, drug content and in-vitro release of methocarbamol with its release kinetic model..$^{30}$

\section{MATERIALS AND METHODS}

Methocarbamol obtained as gift sample from Swapnroop Drugs, Maharashtra. Acconon oil gift sample from Abitec Corporation Limited, USA. The tween 80, carbapol 934, sodium benzoate, ethanol, triethanolamine and all other chemicals used in this study were purchased form Rankem Chemicals, Mumbai.

\section{Methods}

\section{Excipient Compatability Studies}

The drug is associated with one or more than one excipient, which influences the stabilization of the drug. The data of drug and other excipients relations is crucial for choosing proper ingredients which are done by using Fourier Transform-Infrared spectrophotometer (FTIR) study.

\section{Fourier Transform-Infrared spectrophotometer Studies}

FT-IR is basically used to measure the compatibility of drug and excipients. FT-IR is a better analytical instrument for transmission and describing of polymer. The FT-IR spectrum of pure drug, surfactant (Tween 80), other excipients and the final formulation with drug and surfactant were obtained to characterise the possible interaction between drug and excipients if any. FT-IR spectra of pure drug (Methocarbamol), surfactant (Tween 80), and a mixture of the drug with selected surfactant and oil are recorded via a $\mathrm{KBr}$ stub in FT-IR spectrophotometer. \% Transmittance $(\% \mathrm{~T})$ is documented in the spectral area of $4000-400 \mathrm{~cm}^{-1}$. The characteristic peaks of functional groups for distinct samples are done.

\section{Preparation of Nanoemulgel}

About 1\% of drug (Methocarbamol) weight were taken and dissolved in oil (Acconon) in w/v. Nanoemulsion have prepared by selecting the various concentration of surfactant (Tween 80 ) with fixed concentration of oil. The formulation was prepared in various ratios of $1: 2$, $1: 3,1: 5,1: 7.5,1: 10$. 
About $0.75 \mathrm{~g}$ of Acconon oil weighed and $0.05 \mathrm{~g}$ of drug dissolved, followed by Tween 80 in various ratios were added. Further the required quantity of water has added and sonicated the mixture by ultrasonication method using probe sonicator for $20 \mathrm{~min}$ to attain translucent nanoemulsion. Instantaneously preparing a gel formulation with appropriate weighed quantity $(0.1 \mathrm{~g})$ of carbapol-934 have dissolved in sufficient quantity of double distilled water for swelling, followed by addition of $0.1 \mathrm{~g}$ of ethanol, $0.1 \mathrm{~g}$ of sodium benzoate, $0.5 \mathrm{~mL}$ of polyethylene glycol w/v and sufficient quantity of triethanolamine were mixed for thickening to the gel formation. The prepared Methocarbamol loaded nanoemulsion was poured into the gel formulation with constant stirring till the clear homogeneous nanoemulgel obtained. The developed Methocarbamol loaded nanoemulgel have store in eppendorf tubes at room temperature for further evaluations. The formulated nanoemulgel composition is given in Table 1.

\section{Characterization of Methocarbamol Loaded Nanoemulgel}

The nanoemulgel $\mathrm{pH}$ has measured using a $\mathrm{pH}$ meter (Pico $\mathrm{pH}$ Meter). The nanoemulsion and nanoemulgel viscosity was measured by a viscometer (Brookfield DV-E viscometer) which has twisted for 10 mins at 100 rotations at the maximum per min within spindle. The spreadability evaluation were performed by aligning the spreading measurement conducted by keeping the formulated nanoemulgel between two glass slides. Briefly, the weighed amount $(0.5 \mathrm{~g})$ of test and put at the focal point of the glass plate and squeezed between the slides then estimated the spreadabilty of the gel in $\mathrm{cm}$ following $5 \mathrm{~min}$.

\section{Particle Size and Zeta Potential}

Droplet size and zeta potential of the formulated Methocarbamol infused nanoemulgel was analyzed with DLS (dynamic light scattering) method with the help of Horiba Particle Size Analyzer, USA. The nanoemulgel and nanoemulsion was diluted to $200 \mu \mathrm{L}$ in water, from that $50 \mu \mathrm{L}$ diluted to $2 \mathrm{~mL}$ with water and analysed.

\section{Transmission Electron Microscopy (TEM)}

The surface morphology of methocarbamol loaded formulations like both Nanoemulsion and Nanoemulgel has determined using a TEM (Transmission Electron Microscope) instrument. A droplet of formulation was kept in a membrane coated grid and dried in hot air oven. TEM images were analyzed from working on $200 \mathrm{kV}$ voltage.

\section{Drug content}

In the developed formulation the drug content was measured, about $1 \mathrm{~g}$ of nanoemulgel were dissolving in PBS (pH7.4) and make up to $10 \mathrm{~mL}$. The solution was filtered with membrane filter $0.45 \mu$ and diluted preferably, further the absorbance was measured at $273 \mathrm{~nm}$. Buffer used as a blank solution. The formula for calculating the drug content as follows:

\section{Weight of Methocarbamol}

$$
\text { Drug content }(\%)=\frac{\text { in formulation }}{\text { Weight of formulation }} \times 100
$$

\section{In-vitro Methocarbamol Release Studies}

In-vitro drug release studies was done for both the formulation of Nanoemulsions and Nanoemulgel for comparing the release of drug. The different ratio of formulation was performed in phosphate buffer solution ( $\mathrm{pH}$ 7.4), under ideal sink conditions using dialysis membrane (M.Wt cut off $12 \mathrm{KD}$ ) on Franz diffusion cell technique. The $1 \mathrm{~g}$ of formulation sample was placed on dialysis membrane mounted on the donor compartment of franz diffusion cell and

\begin{tabular}{|c|c|c|c|c|c|c|c|c|}
\hline \multirow[b]{2}{*}{ S.No. } & \multirow[b]{2}{*}{ Formulation Code } & \multicolumn{7}{|c|}{ Ingredients (10 gm) } \\
\hline & & 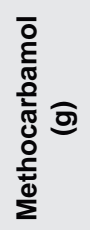 & 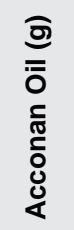 & 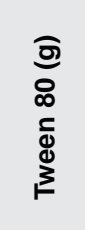 & 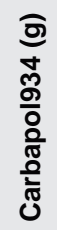 & $\frac{\text { J }}{\underline{\Xi}}$ & ह 일 & 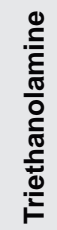 \\
\hline 1. & Nanoemulgel $2 \%$ & 0.05 & 0.75 & 0.1 & 0.1 & 0.5 & 0.1 & Q.S \\
\hline 2. & Nanoemulgel 3\% & 0.05 & 0.75 & 0.15 & 0.1 & 0.5 & 0.1 & Q.S \\
\hline 3. & Nanoemulgel 5\% & 0.05 & 0.75 & 0.25 & 0.1 & 0.5 & 0.1 & Q.S \\
\hline 4. & Nanoemulgel $7.5 \%$ & 0.05 & 0.75 & 0.375 & 0.1 & 0.5 & 0.1 & Q.S \\
\hline 5. & Nanoemulgel $10 \%$ & 0.05 & 0.75 & 0.5 & 0.1 & 0.5 & 0.1 & Q.S \\
\hline
\end{tabular}


the reservoir part filled with $18 \mathrm{~mL}$ of PBS ( $\mathrm{pH} 7.4)$ solution by appropriate temperature $\left(37^{\circ} \mathrm{C}\right)$ with continuing magnetic stirring at $600 \mathrm{rpm}$. At relative time interval of 1 to $7 \mathrm{hr}$ aliquot amount of sample $(2 \mathrm{~mL})$ was withdrawn and replace it with $2 \mathrm{~mL}$ of $\mathrm{pH} 7.4$ buffer solution poured into a receptor compartment to continue the perfect sink condition. The drug release content of the samples was measured by diluting with PBS solution ( $\mathrm{pH} 7.4$ ) and by absorbing the nanometer using UV spectrophotometer at $273 \mathrm{~nm}$. The graph is plotted with \% Drug release verses Time. The pattern of drug release mechanism of non-linear kinetic model was treated by fitting the various release kinetic models to evaluate the zero order, first order, higuchi release model, hixon crowell model and korsmeyer peppas model.

\section{RESULTS AND DISCUSSION}

\section{Drug Excipient Compatibility Studies}

The drug's stability is influenced when it comes into contact with one or more excipients. The information of interactions of excipients with drug is essential for choosing appropriate excipients which are done by using Fourier Transform-Infrared spectrophotometer (FT-IR) study.

The FT-IR spectra of Methocarbamol shows the characteristic peaks of carboxylic acid (2943-3439.08), $\mathrm{NH}$ bend (1508.33-1602), C=O stretch (1674.21), C-H bend (758.02-833.25), -C-H bend (960.55), C-O stretch (at 1249.87-1184.29) and C-O-C stretch (1060.851082.07). The projecting peak of Methocarbamol was observed and when incorporated with other excipient there was no interactions were found. The FT-IR spectra of Methocarbamol, Acconon oil, Tween 80, carbapol 934, Sodium benzoate, PEG, Triehanolamine and 10\% Nanoemulgel formulation and drug excipient physical mixture were shown in Figure 1 to 8 and their respected peaks represented in Table 2 to 9 .

The strong absorption peak observed at 1674 and 1695 $\mathrm{cm}^{-1}$ could be recognized to carbonyl group vibrational stretching of Methocarbamol in Nanoemulgel 10\%. Spectrum of formulation shows mild shift towards 1643 evident that carbonyl group stretching of methocarbamol and confirms that there was no chemical change. The formation of intermolecular hydrogen bonding at 3500 to $3400 \mathrm{~cm}^{-1}$ indicating the enhancing the solubilization capacity of the formulation.

\section{Physicochemical Characterization}

The physicochemical characterizations of the developed Methocarbamol loaded nanoemulsion are represented
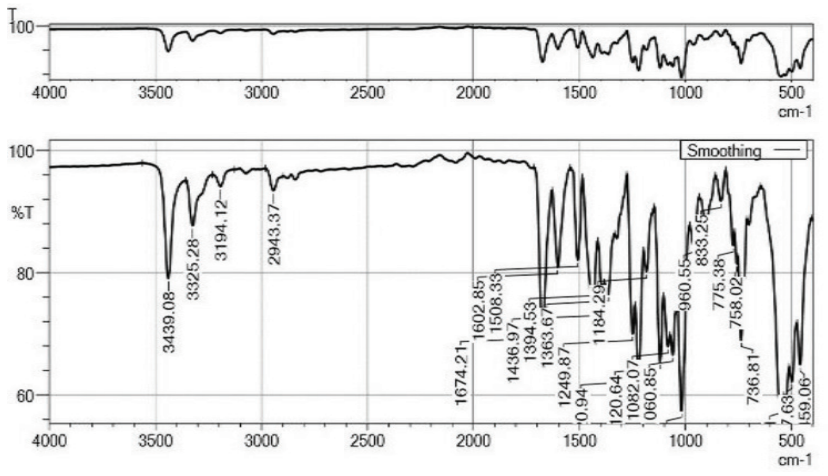

Figure 1: FT-IR spectra of Methocarbamol.
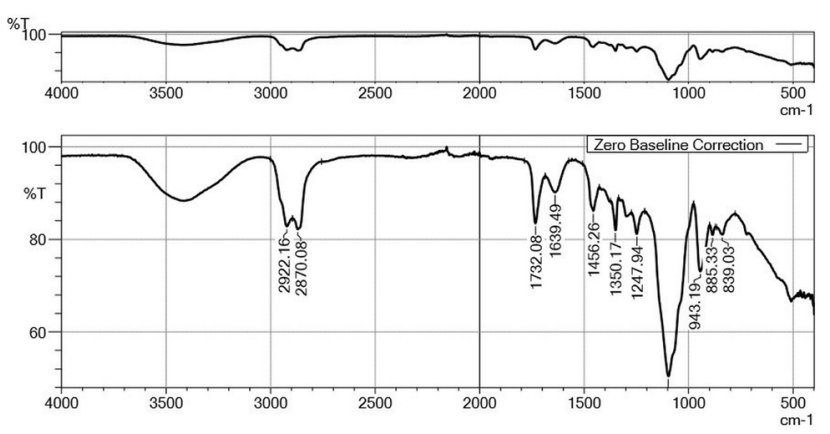

Figure 2: FT-IR spectra of Acconon.
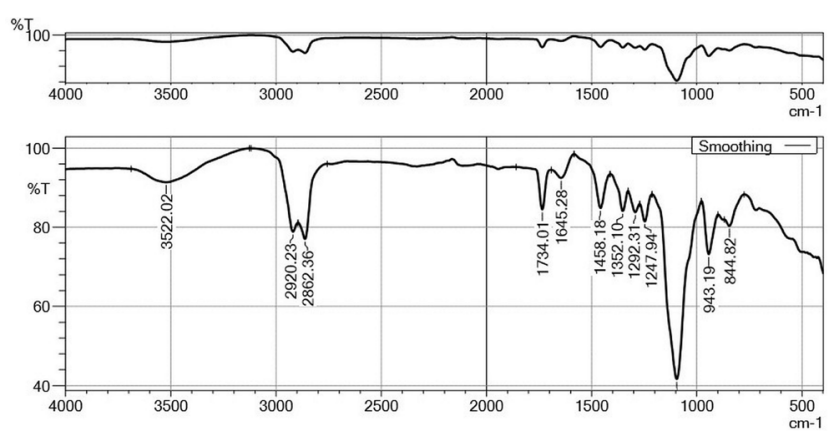

Figure 3: FT-IR spectra of Tween 80.
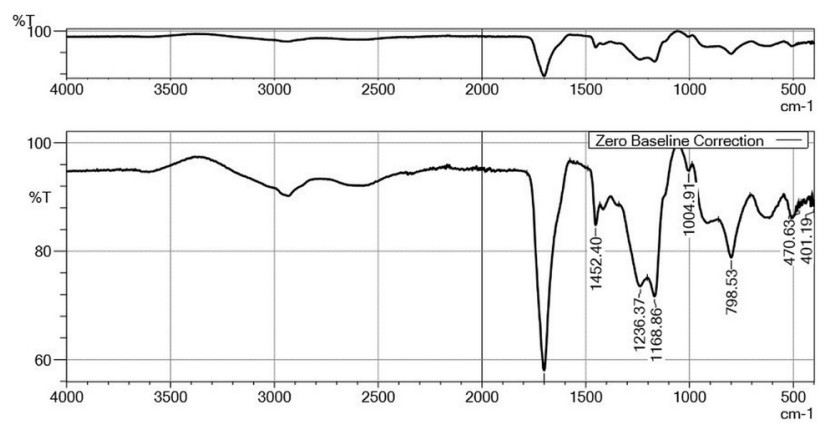

Figure 4: FT-IR spectra of Carbapol 934. 

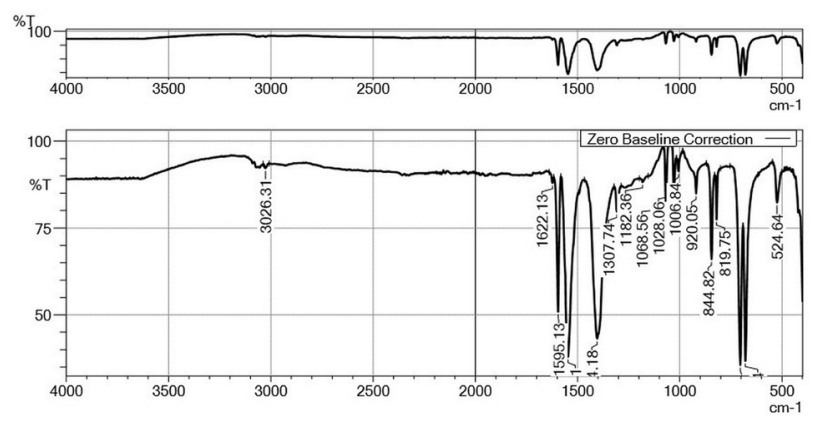

Figure 5: FT-IR spectra of Sodium Benzoate.
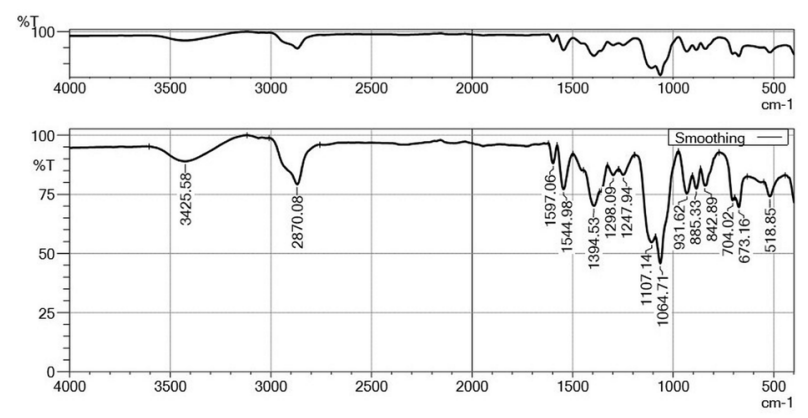

Figure 6: FT-IR spectra of Polyethylene Glycol.
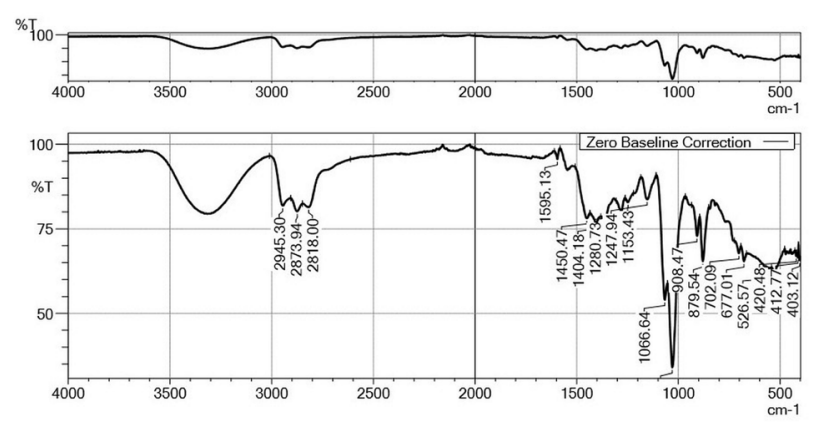

Figure 7: FT-IR spectra of Triethanolamine.
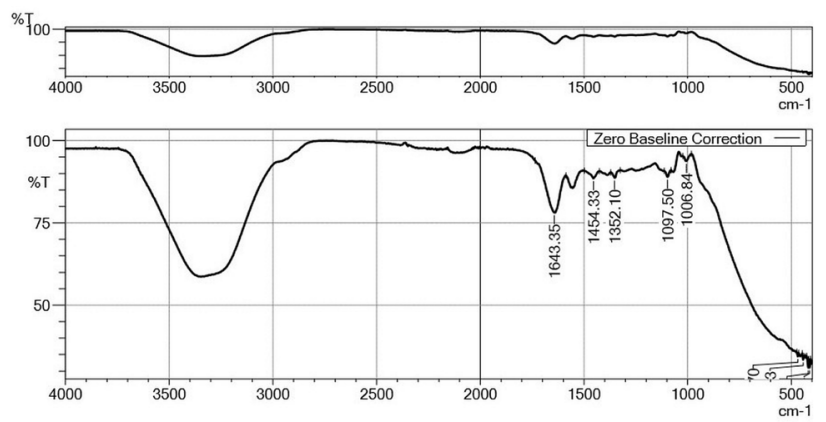

Figure 8: FT-IR spectra of Nanoemulgel $10 \%$.

\begin{tabular}{|c|c|c|c|}
\hline \multicolumn{4}{|c|}{ Table 2: The Main Characteristic Peak of } \\
Methocarbamol. \\
\hline $\begin{array}{c}\text { S } \\
\text { No. }\end{array}$ & $\begin{array}{c}\text { Functional } \\
\text { group }\end{array}$ & Peaks (cm ${ }^{-1}$ ) & Bonds \\
\hline 1 & Carboxylic & $2943-3439.08$ & s, broad O-H stretch \\
\hline 2 & NH bend & 960.55 & w-m N-H bend \\
\hline 3 & Aldehyde & 1674.21 & s C=O stretch \\
\hline 4 & Aromatics & $758.02-833.25$ & s C-H bend \\
\hline 5 & Alkenes & 960.55 & s =C-H bend \\
\hline 6 & Alcohols & $1184.29-1249.87$ & m-s C-O stretch \\
\hline 7. & Ether & $1060.85-1082.07$ & s C-O-C stretch \\
\hline
\end{tabular}

\begin{tabular}{|c|c|c|c|}
\hline \multicolumn{4}{|c|}{$\begin{array}{c}\text { Table 3: The Main Characteristic Peak of Acconon } \\
\text { Oil. }\end{array}$} \\
\hline S No. & Functional group & Peaks $\left(\mathrm{cm}^{-1}\right)$ & Bonds \\
\hline 1 & Alkanes and alkyls & $2922.16-2870$ & s C-H stretch \\
\hline 2 & Ketones & $1639.49-1732$ & $\mathrm{~s} \mathrm{C}=\mathrm{O}$ stretch \\
\hline 3 & Alkanes and alkyls & 1456.26 & s C-H bend \\
\hline 4 & Alkyl halides & 1350.17 & vs C-F stretch \\
\hline 5 & Alkenes & 885.35-943.19 & $\mathrm{S}=\mathrm{C}-\mathrm{H}$ bend \\
\hline
\end{tabular}

\begin{tabular}{|c|c|c|c|}
\hline $\begin{array}{l}\text { S } \\
\text { No. }\end{array}$ & Functional group & Peaks $\left(\mathrm{cm}^{-1}\right)$ & Bonds \\
\hline 1 & Carboxylic acid & 3522.02 & $\begin{array}{l}\mathrm{s} \text {, broad O-H } \\
\text { stretch }\end{array}$ \\
\hline 2 & Alkanes and alkyls & $2862.36-2920.23$ & s C-H stretch \\
\hline 3 & Aldehydes & $1645.28-1734.01$ & s C $=0$ stretch \\
\hline 4 & Alkanes and alkyls & 1458.18 & $\mathrm{~s} \mathrm{C}-\mathrm{H}$ bend \\
\hline 5 & Alkenes & 885.33-943.19 & $\mathrm{S}=\mathrm{C}-\mathrm{H}$ bend \\
\hline 6 & Ethers & 1247.94 & $\begin{array}{c}\text { m-s }=\mathrm{C}-\mathrm{O}-\mathrm{C} \\
\text { sym\&asym } \\
\text { stretch }\end{array}$ \\
\hline 7 & Alkyl halides & 1292.31 & vs C-F stretch \\
\hline
\end{tabular}

Table 5: The Main Characteristic Peaks of Carbapol
934.


in Table 10. The $\mathrm{pH}$ of all the Nanoemulsion (NE) formulations and Nanoemulgel formulations were around 5 to 7 and the viscosity was in the range of 18.22 to $45.25 \mathrm{cp}$. It has better spreadability range from $3.3 \mathrm{~cm}$ to $7.2 \mathrm{~cm}$ indicates the suitability of quick spreadable for the topical application.

\section{Particle Size and Zeta potential}

The mean globule size was found to be $20.1 \mathrm{~nm}, 10.6 \mathrm{~nm}$, $73.8 \mathrm{~nm}, 63.8 \mathrm{~nm}$ and $56.4 \mathrm{~nm}$ and zeta potential

\begin{tabular}{|c|c|c|c|}
\multicolumn{4}{|c|}{ Table 6: The Main Characteristic Peaks of Sodium } \\
Benzoate. \\
\hline $\begin{array}{c}\text { S } \\
\text { No. }\end{array}$ & Functional group & Peaks (cm ${ }^{-1}$ ) & Bonds \\
\hline 1 & Alkenes & 3026.31 & $\begin{array}{c}\text { W-m }=\text { C-H } \\
\text { stretch }\end{array}$ \\
\hline 2 & Amides & 1622.13 & m-s N-H bend \\
\hline 3 & Aromatics & 1595.13 & $\begin{array}{c}\text { m-s ring C=C } \\
\text { stretch }\end{array}$ \\
\hline 4 & Alkanes and alkyls & 524.64 & C-I stretch \\
\hline 5 & Alkyl halides & 1307.74 & vs C-F stretch \\
\hline 6 & Alkenes & $844.82-920.05$ & s =C-H bend \\
\hline 7 & Alcohol & 1182.36 & m-s C-O stretch \\
\hline
\end{tabular}

\begin{tabular}{|c|c|c|c|}
\hline \multicolumn{4}{|c|}{$\begin{array}{c}\text { Table 7: The Main Characteristic Peaks of } \\
\text { Polyethylene Glycol. }\end{array}$} \\
\hline S No. & $\begin{array}{c}\text { Functional } \\
\text { group }\end{array}$ & Peaks (cm $^{-1}$ ) & Bonds \\
\hline 1 & Carboxylic acid & $2870.08-3425.58$ & $\begin{array}{c}\text { s, broad O-H } \\
\text { stretch }\end{array}$ \\
\hline 2 & Amides & $1450.47-1597.06$ & m-s N-H bend \\
\hline 3 & Alcohol & 1247.94 & m-s C-O stretch \\
\hline 4 & $\begin{array}{c}\text { Alkanes and } \\
\text { alkyls }\end{array}$ & 524.64 & C-I stretch \\
\hline 5 & Alkyl halides & 1064.71 & vs C-F stretch \\
\hline 6 & Alkenes & $842.89-931.62$ & s =C-H bend \\
\hline 7 & Alkenes & $673.16-704.02$ & m-s =C-H bend \\
\hline
\end{tabular}

were found to be in the range of $-0.1 \mathrm{mV}$ to $0.3 \mathrm{mV}$ respectively for the formulation of Nanoemulsion 3\%, $5 \%, 7.5 \%$ and $10 \%$ accordingly. Zeta potential value is closer to zero owing to the appearance of tween 80 is non-ionic surfactant (Figures 9 and 10). Mostly attain using a various concentration of surfactant with optimal sonication.

\section{Drug Content}

The drug loading study resulting that the formulations of $3 \%, 5 \%, 7.5 \%$ and $10 \%$ drug loading of $86.66 \%$, $87.4 \%, 94.04 \%$, and 97.77 respectively. This indicates increasing the oil concentration promotes the higher volume of drug loading capacity.

\section{TEM (Morphology of the Formulation)}

TEM for the processed formulation was studied using (TEM-2100 PLUS, Jeol ltd, UK) determined through

\begin{tabular}{|c|c|c|c|}
\hline \multicolumn{4}{|c|}{ Table 8: The Main Characteristic Peaks of } \\
Triethanolamine. \\
\hline $\begin{array}{c}\text { S } \\
\text { No. }\end{array}$ & $\begin{array}{c}\text { Functional } \\
\text { group }\end{array}$ & Peaks $\left(\mathbf{c m}^{-1}\right)$ & Bonds \\
\hline 1 & Carboxylic acid & 2945.30 & $\begin{array}{c}\text { s, broad O-H } \\
\text { stretch }\end{array}$ \\
\hline 2 & Amides & 1595.13 & m-s N-H bend \\
\hline 3 & Alkenes & $2818-2873.94$ & s C-H stretch \\
\hline 4 & Alkyl halides & $403.12-420.48$ & C-I stretch \\
\hline 5 & $\begin{array}{c}\text { Alkanes and } \\
\text { alkyls }\end{array}$ & 1450.47 & s C-H bend \\
\hline
\end{tabular}

\begin{tabular}{|c|c|c|c|}
\hline S No. & Functional group & Peaks $\left(\mathrm{cm}^{-1}\right)$ & Bonds \\
\hline 1 & Alkenes & 1643.35 & $\begin{array}{c}\text { vw-m C }=C \\
\text { stretch }\end{array}$ \\
\hline 2 & Alcohols & 1097.50 & s C-O-C stretch \\
\hline 3 & Alkenes & $1006-1352.10$ & vs C-F stretch \\
\hline 4 & Alkanes and alkyls & 1454.33 & s C-H bend \\
\hline
\end{tabular}

\begin{tabular}{|c|c|c|c|c|c|}
\hline Formulation Code & Drug content* (\%) & $\mathrm{pH}$ & Viscosity* (cps) & Spreadability* $(\mathrm{cm})$ & Drug release* $(\%)$ \\
\hline F1 NEs $3 \%$ & $85.45 \pm 3.3$ & $5.4 \pm 0.1$ & $18.22 \pm 0.2$ & $6.3 \pm 0.3$ & $64.28 \pm 2.8$ \\
\hline F2 NEs $5 \%$ & $88.56 \pm 2.8$ & $5.59 \pm 0.2$ & $19.1 \pm 0.1$ & $6.6 \pm 0.4$ & $50.78 \pm 1.6$ \\
\hline F3 NEs $7.5 \%$ & $95.66 \pm 4.1$ & $5.7 \pm 0.1$ & $19.9 \pm 0.3$ & $7.0 \pm 0.5$ & $41.78 \pm 1.7$ \\
\hline F4 NEs $10 \%$ & $98.24 \pm 4.2$ & $5.47 \pm 0.2$ & $21.2 \pm 0.2$ & $7.2 \pm 0.4$ & $38.57 \pm 1.4$ \\
\hline F5 GEL 3\% & $86.66 \pm 3.2$ & $5.56 \pm 0.2$ & $38.26 \pm 0.4$ & $3.3 \pm 0.1$ & $29.57 \pm 1.1$ \\
\hline F6 GEL 5\% & $87.4 \pm 3.8$ & $5.25 \pm 0.3$ & $40.22 \pm 0.3$ & $3.0 \pm 0.1$ & $38.25 \pm 1.7$ \\
\hline F7 GEL 7.5\% & $94.07 \pm 2.7$ & $7.3 \pm 0.2$ & $42.36 \pm 0.2$ & $4.0 \pm 0.3$ & $43.71 \pm 2.4$ \\
\hline F8 GEL 10\% & $97.77 \pm 2.9$ & $7.16 \pm 0.1$ & $45.25 \pm 0.4$ & $4.2 \pm 0.4$ & $52.39 \pm 2.2$ \\
\hline
\end{tabular}

*number of experiment $n=3$. 


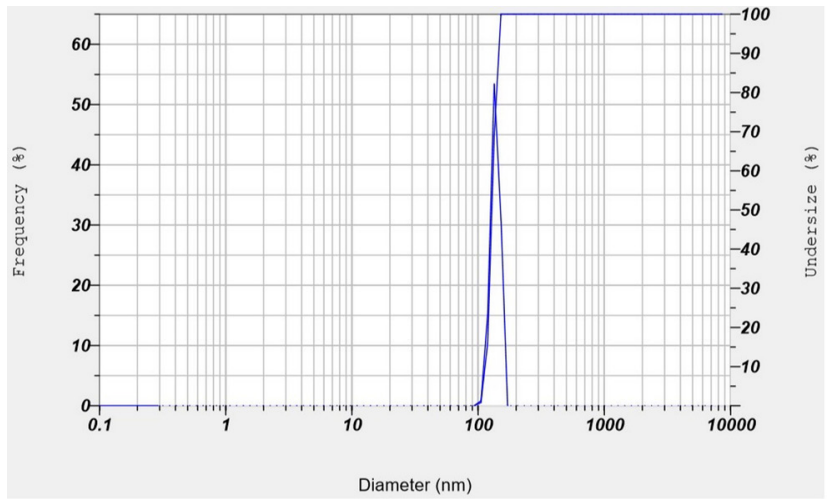

Figure 9: The particle size of $3 \%$ Nanoemulsion.

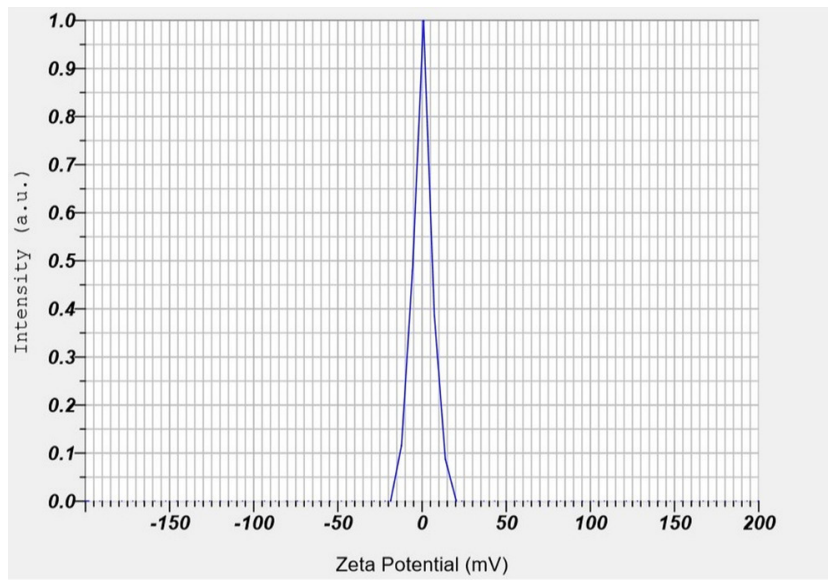

Figure 10: Zeta potential of $3 \%$ Nanoemulsion.

$70-80 \mathrm{KV}$ at 5000 magnification. The TEM results displayed in Figure $11 \mathrm{a} \& \mathrm{~b}$, that the droplet size was of nanometer in size range with uniform, spherical and smooth surface.

\section{In-vitro Drug Release}

The methocarbamol release studies of NEs, NE-Gel and conventional suspension were performed using dialysis membrane on the Franz diffusion cell, PBS (pH7.4) as release media with $37^{\circ} \mathrm{C}$. The in-vitro drug release of drug from the NE, NEs-Gel after $7 \mathrm{hr}$ showed the following order of release and the NE 3\% and NE-Gel $10 \%$ showed the highest release of 64.28 and $52.39 \%$ at $24 \mathrm{hr}$, (Figure 12) which is due the presence of the higher amount ACCONON oil, in the formulation.

The in-vitro release data of Methocarbamol loaded NEs and NE-gel the rapid release followed along with steady manner of release was determined and the Methocarbamol release were accordingly with formulation of $3 \%, 5 \%, 7.5 \%$ and $10 \%$ respectively. The volume of drug release for 3\% Nanoemulsion is

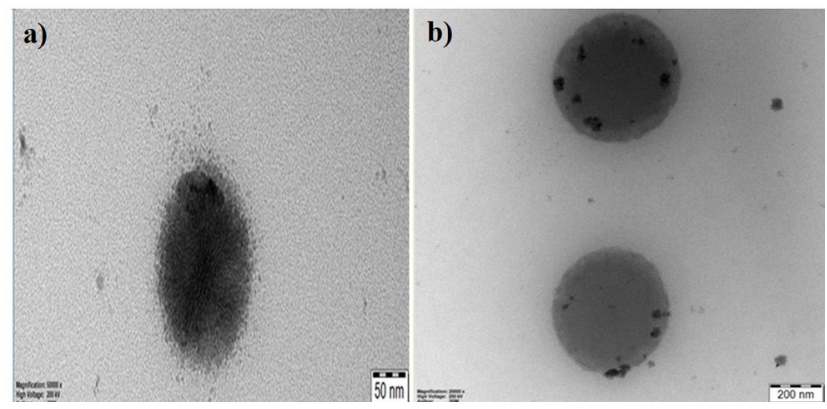

Figure 11: a) TEM image of Nanoemulgel and b) Nanoemulsion.

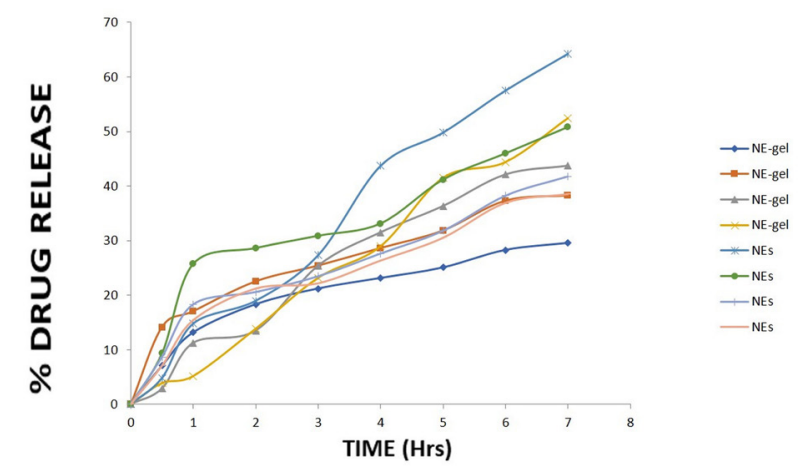

Figure 12: \% Drug Release of All the Formulation.

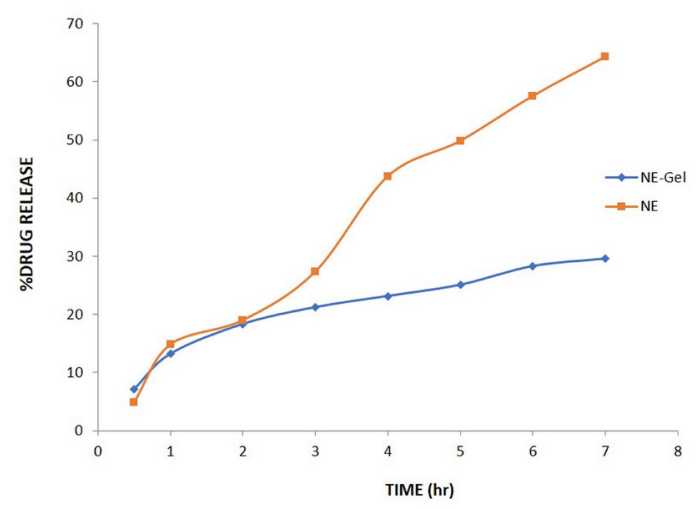

Figure 13: Comparing the both Nanoemulsion and Nanoemulgel drug release.

$64.28 \%, 50.78 \%, 41.78 \%, 38.57 \%$ and $3 \%$ Nanoemulgel is $29.57 \%, \quad 38.25 \%, 43.71 \%, \quad 52.39 \%$ respectively. The in-vitro Methocarbamol release profile of 3\% nanoemulsion has compared with its nanoemulgel due to higher quantity of oil, in-vitro resulting increased drug release are shown in Figure 13.

According to drug release kinetic model, various formulation of Nanoemulsion were prepared in that first order release kinetics shows best fit for 3\% 


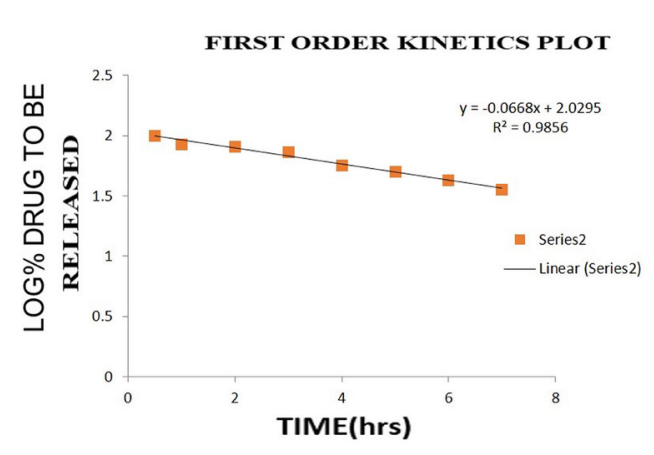

Figure 14: In vitro release kinetics of zero order kinetics model.

Nanoemulgel with its maximum $\mathrm{R}^{2}$ value is 0.9856 are shown in Figure 6 and first order represents the systems where the drug release was dependent of its concentration. While zero order release model $R^{2}=0.9835$, Higuchi model $R^{2}=0.6769$, kormeyer peppas model $R^{2}=0.9714$ and Hixson crowell model $R^{2}=0.984$ respectively. In-vitro release data were shown in Figure 14.

\section{CONCLUSION}

The aim of this work is to develop and optimise a stable nanoemulgel loaded with skeletal muscle relaxant drug Methocarbamol, by ultrasonication method of preparing oil in water type nanoemulsion. The primary objective of the work was the compatibility studies to characterize the nanoemulgel meant for the following Solubility, droplet size, zeta potential, $\mathrm{pH}$, viscosity, spreadability, TEM for morphology of formulation, drug content and in-vitro release. Methocarbamol is skeletal muscle relaxant is used in the formulation of Nanoemulgel, to prove that nanoemulgel is having maximum drug release when comparing it with oil in water type nanoemulsion preparation and its prepared by sonication method using appropriate quantity of ingredients as Acconon is considered as oil phase, Tween 80 is surfactant and co-surfactant, carbapol 934, sodium benzoate and triethanolamine these are all used for hydrogel preparation accordingly. The NEs were formulated using varying the concentration of Tween 80 by ultrasonication method to obtain stable NEs. The formulation was further evaluated for its physicochemical properties. It possess the $\mathrm{pH}$ of $5-7$, viscosity of $18.22 \mathrm{cps}$, droplet size of $10.6 \mathrm{~nm}$ and zetapotential of $0.1 \mathrm{mV}$. The formulated Nanoemulsion hydrogel preparation were admixed with carbapol hydrogel to form a nanoemulgel. Using franz diffusion cell, in-vitro release studies was performed and most of the formulation possess better quality of drug release. Based on in-vitro release it was found that $3 \%$ of Nanoemulsion possessed maximum drug release shows $64.28 \%$ when comparing with it $3 \%$ of nanoemulgel $29.57 \%$. The NE (3\%) exhibiting the highest drug release and NE-Gel shows slower release due the amount of surfactant and hydrogel present in the formulation and maximum amount of Acconon oil content, lower size of the droplet when compared to the conventional formulation. Hence, we conclude that the developed NE, NE-Gel might be beneficial for the better topical delivery of muscle relaxant drug.

\section{ACKNOWLEDGEMENT}

Authors are thankful to the Management of SRM College of Pharmacy, Kattankulathur.

\section{CONFLICT OF INTEREST}

The authors declare that there is no conflict of interest.

\section{ABBREVIATIONS}

NE: Nanoemulsion;FTIR: Fourier Transform-Infrared spectrophotometer; \%T: Percentage Transmittance; DLS: dynamic light scattering; TEM: Transmission Electron Microscope; PBS: Phosphate Buffer Solution; M.Wt: Molecular Weight; UV: Ultraviolet.

\section{REFERENCES}

1. Miller TM, Layzer RB. Muscle cramps. Muscle Nerve. 2005;32(4):431-42. doi: 10.1002/mus.20341, PMID 15902691.

2. Schwellnus MP. Muscle cramping in the marathon: aetiology and risk factors. Sports Med. 2007;37(4-5):364-7. doi: 10.2165/00007256-200737040-00023, PMID 17465609.

3. Schwellnus MP. Cause of exercise associated muscle cramps (EAMC)-altered neuromuscular control, dehydration or electrolyte depletion? $\mathrm{Br}$ J Sports Med. 2009;43(6):401-8. doi: 10.1136/bjsm.2008.050401, PMID 18981039.

4. Schwellnus MP, Drew N, Collins M. Muscle cramping in athletes--risk factors, clinical assessment, and management. Clin Sports Med. 2008;27(1):183-94, ix. doi: 10.1016/j.csm.2007.09.006, PMID 18206574.

5. Salt E, Gokun Y, Rankin Kerr A, Talbert J. A Description and Comparison of Treatments for Low Back Pain in the United States. Orthop Nurs. 2016;35(4):214-21. doi: 10.1097/NOR.0000000000000258. PMID 27441875.

6. Bhatia A, Engle A, Cohen SP. Current and future pharmacological agents for the treatment of back pain. Expert Opin Pharmacother. 2020;21(8):857-61. doi: 10.1080/14656566.2020.1735353, PMID 32124653.

7. Jahan F, Nanji K, Qidwai W, Qasim R. Fibromyalgia syndrome: an overview of pathophysiology, diagnosis and management. Oman Med J. 2012;27(3):192-5. doi: 10.5001/omj.2012.44, PMID 22811766.

8. Redillas C, Solomon S. Prophylactic pharmacological treatment of chronic daily headache. Headache. 2000;40(2):83-102. doi: 10.1046/j.15264610.2000.00014.x, PMID 10759908.

9. Agostoni EC, Barbanti P, Calabresi P, Colombo B, Cortelli P, Frediani F, Geppetti P, Grazzi L, Leone M, Martelletti P, Pini LA, Prudenzano MP, Sarchielli P, Tedeschi G, Russo A, Italian chronic migraine group. Current and 
emerging evidence-based treatment options in chronic migraine: A narrative review. J Headache Pain. 2019;20(1):92. doi: 10.1186/s10194-019-1038-4, PMID 31470791.

10. Ha HA, Gonzalez A. Migraine headache prophylaxis. Am Fam Physician. 2019;99(1):17-24. PMID 30600979.

11. Brogden RN, Speight TM, Avery GS. Baclofen: a preliminary report of its pharmacological properties and therapeutic efficacy in spasticity. Drugs. 1974;8(1):1-14. doi: 10.2165/00003495-197408010-00001, PMID 4154834.

12. Chang E, Ghosh N, Yanni D, Lee S, Alexandru D, Mozaffar T. A review of spasticity treatments: pharmacological and interventional approaches. Crit Rev Phys Rehabil Med. 2013;25(1-2):11-22. doi: 10.1615/ CritRevPhysRehabilMed.2013007945, PMID 25750484.

13. Ghai A, Garg N, Hooda S, Gupta T. Spasticity - pathogenesis, prevention and treatment strategies. Saudi J Anaesth. 2013;7(4):453-60. doi: 10.4103/1658354X.121087, PMID 24348300.

14. Aljuhani O, Kopp BJ, Patanwala AE. Effect of methocarbamol on acute pain after traumatic injury. Am J Ther. 2017;24(2):e202-6. doi: 10.1097/ MJT.0000000000000364, PMID 26469684.

15. Park HJ, Moon DE. Pharmacologic management of chronic pain. Korean J Pain. 2010;23(2):99-108. doi: 10.3344/kjp.2010.23.2.99, PMID 20556211.

16. Patanwala AE, Aljuhani O, Kopp BJ, Erstad BL. Methocarbamol use is associated with decreased hospital length of stay in trauma patients with closed rib fractures. Am J Surg. 2017;214(4):738-42. doi: 10.1016/j. amjsurg.2017.01.003, PMID 28088301.

17. Friedman BW, Cisewski D, Irizarry E, Davitt M, Solorzano C, Nassery A, Pearlman S, White D, Gallagher EJ. A Randomized, Double-Blind, PlaceboControlled Trial of Naproxen With or Without Orphenadrine or Methocarbamol for Acute Low Back Pain. Ann Emerg Med. 2018;71(3):348-356.e5. doi: 10.1016/j.annemergmed.2017.09.031, PMID 29089169.

18. Leppert W, Malec-Milewska M, Zajaczkowska R, Wordliczek J. Transdermal and Topical Drug Administration. Transdermal and Topical Drug Administration in the Treatment of Pain. Molecules. 2018;23(3):681. doi: 10.3390/molecules23030681, PMID 29562618.
19. Schmidts T, Dobler D, Nissing C, Runkel F. Influence of hydrophilic surfactants on the properties of multiple W/O/W emulsions. J Colloid Interface Sci. 2009;338(1):184-92. doi: 10.1016/j.jcis.2009.06.033, PMID 19595359.

20. Solans C, Izquierdo P, Nolla J, Azemar N, Garciacelma M. Nano-emulsions. Curr Opin Colloid Interface Sci. 2005;10(3-4):102-10. doi: 10.1016/j. cocis.2005.06.004.

21. Eid A, Elmarzugi NA, El-Enshasy HA, Arafat OM. A novel Swietenia macrophylla oil self-nanoemulsifying system: development and evaluation. Int J Pharm Pharm Sci. 2013;5:639-44.

22. Chen $\mathrm{H}$, Khemtong $\mathrm{C}$, Yang $\mathrm{X}$, Chang $\mathrm{X}$, Gao J. Nanonization strategies for poorly water-soluble drugs. Drug Discov Today. 2011;16(7-8):354-60. doi: 10.1016/j.drudis.2010.02.009, PMID 20206289.

23. Tamilvanan S. Oil-in-water lipid emulsions: implications for parenteral and ocular delivering systems. Prog Lipid Res. 2004;43(6):489-533. doi: 10.1016/j.plipres.2004.09.001, PMID 15522762.

24. Panwar A, Upadhyay N, Bairagi M, Gujar S, Darwhekar GN. Emulgel: a review. Asian J Pharm Life Sci. 2011;1:333-43.

25. Ghai I, Chaudhary H, Ghai S, Kohli K, Kr V. A review of transdermal drug delivery using nano-vesicular carriers: Transfersomes. Recent Pat Nanomed. 2012;2(2):164-71. doi: 10.2174/1877912311202020164.

26. Ajazuddin, Alexander A, Khichariya A, Gupta S, Patel RJ, Giri TK, Tripathi DK. Recent expansions in an emergent novel drug delivery technology: emulgel. J Control Release. 2013;171(2):122-32. doi: 10.1016/j.jconrel.2013.06.030, PMID 23831051.

27. Emulgel BJ. A comprehensive Review on the Recent Advances in Topical Drug Delivery. Int Res J Pharm. 2011;2:60-70.

28. Shah AA. Emulgel: A topical prepration for hydrophobic drugs. Pharm Tech Med. 2013;2:370-6.

29. Kumar L, Verma R. In vitro evaluation of topical gel prepared using natural polymer. Int J Drug Delivery. 2010;2(1):58-63. doi: 10.5138/ ijdd.2010.0975.0215.02012.

30. Lakshmana PS, Sharvanan S, Aravindan S, Bhuvaneswari A, Manikandan V. Nanoemulgel for transdermal Delivery of cyclobenzaprine hydrochloride: design, Characterization and in-vitro Studies. Appro Drug Dev. 2017;1(5)(v):5.

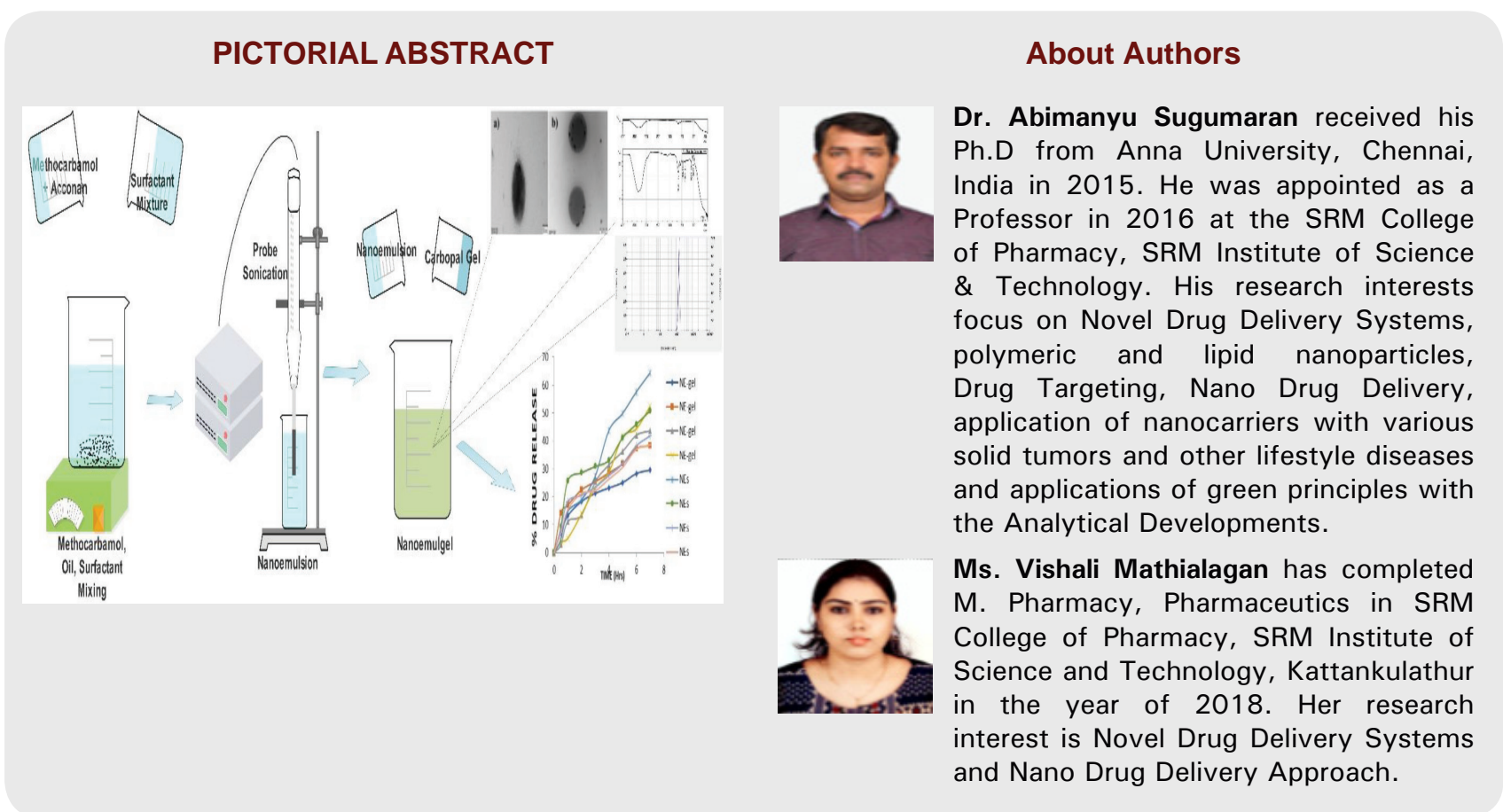

Cite this article: Sugumaran A, Mathialagan V. Topical Delivery of Methocarbamol Loaded Nanoemulgel - in vitro Characterization. Indian J of Pharmaceutical Education and Research. 2022;56(1):144-52. 